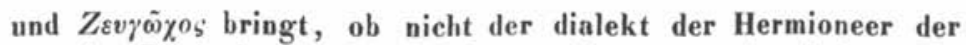
severior Doris in manchen punkten näher gestanden habe. Bestätigung für Argolis gewährt unsre inschrift, welche nirgend unreinen dorismus verräth, obschon die alte eigenheit der Argiver, ovs statt des spätern ov' zu behalten, bereits erloschen ist

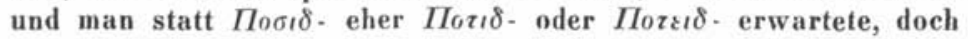
vgl. Ahrens p. $243 \mathrm{f}$. Ueberhaupt, je mehr ältere monumente her. vorgezogen werden, desto mehr der gesammten Doris gemeinsames tritt zu tage, so unantastbar die scheidung der beiden species im grossen ist. Ich erinnre nur an die wunderbare lokrische inschrift von Chaleion oder Oiantheia, welche auch in dialektischer hinsicht äusserst lehrreich ist. So dürfen wir nach dem oben p. 181 bemerkten getrost $\gamma \varrho \circ \varphi$ - der gesammten mundart älterer zeit beilegen, wie es hier 15 in $\gamma \rho o q z \dot{v} s$ erscheint und

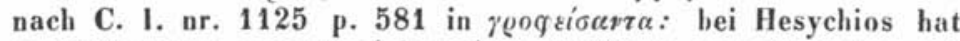

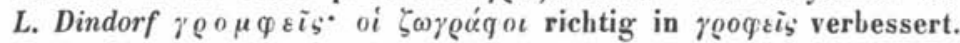
Noch folgendes im einzelnen.

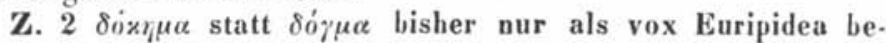
kannt. Aber Pindar hat doch $\delta\llcorner\delta 0 \% \eta \mu \varepsilon v o s$ und man darf nun nicht mehr mit Alırens p. 340 bloss $\varepsilon^{\sharp} \delta \circ \xi_{\varkappa}$ und $\delta \varepsilon \delta \circ \gamma \mu \alpha \iota$ dorisch

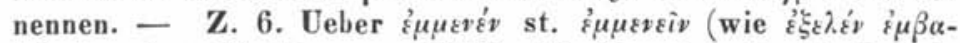

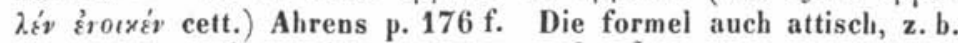

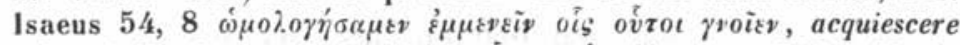
rebus iudicatis. - Z. 7. Ueber $\stackrel{\varepsilon}{q}=\omega s$ Ahrens p. 370. Merk.

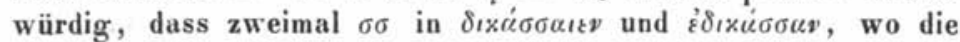
Doris soust ziemlich streng an $\xi$ hält, Ahrens p. 89. 100. 0bschon ausnahmen sich auch dort finden, wonach die ältre Doris auch im fut. und aor. der verba $\zeta \omega$ mit dem leshischen äolis. mus eins war. - Z. 12 vixĩv, vgl. Ahrens p. 195. - Z. 14

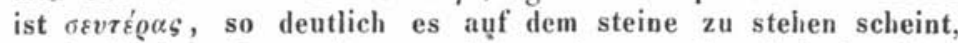
unglaublich. Denn die vom herrn herausgeber beigebrachten

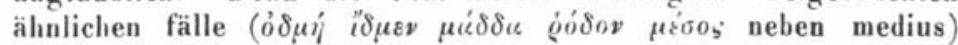
sind nicht geeignet, den verdacht zu unterdrücken, dass- $\sigma$ irrig für $\delta$ gesetzt ist.

Göttingen.

F. W. Schneideroin.

\title{
58. Eudocia. Apollonius. S. Empiricus. Charito.
}

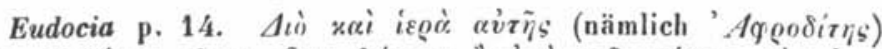

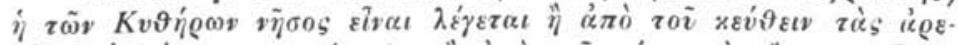

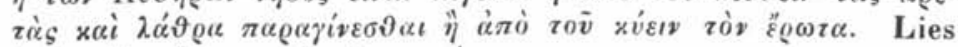

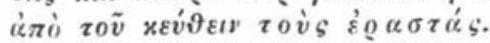

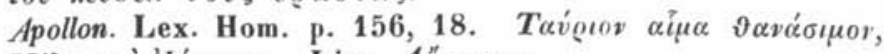

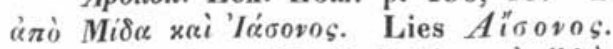

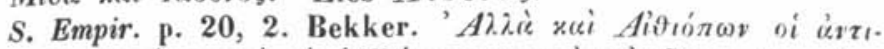

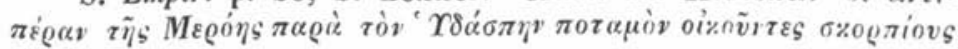




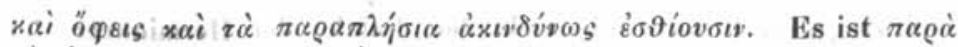

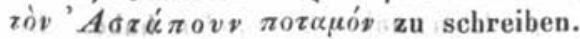

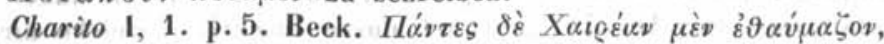

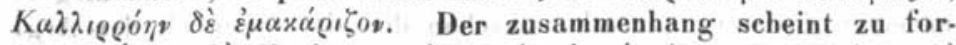

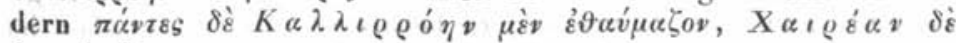

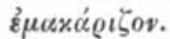

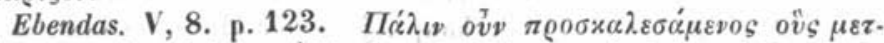

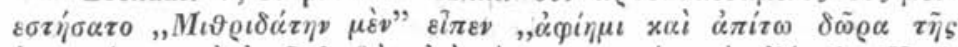

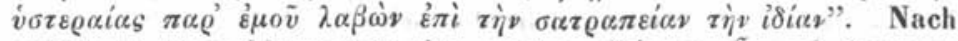

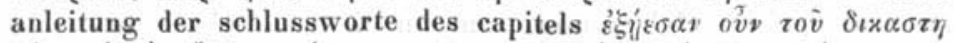

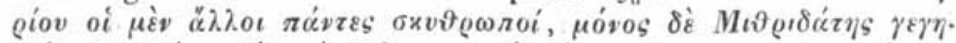

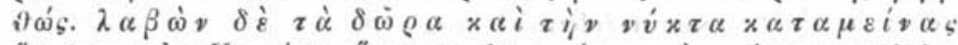

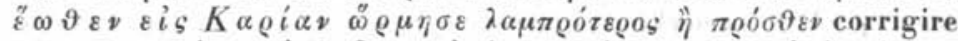

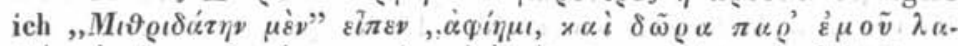

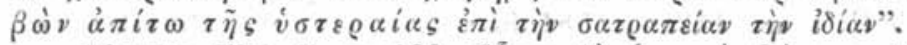

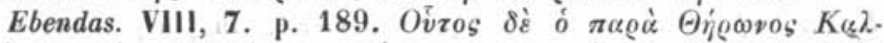

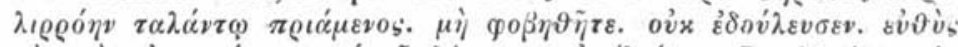

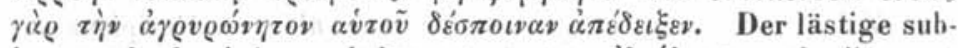
jectswechsel wird vermieden, wenn man $\dot{\varepsilon} \delta 0 v \dot{\lambda} \omega \sigma \varepsilon v$ schreibt.

Rudolstadt.

R. Hercher.

\section{Zu den briefen des Brutus.}

Zur characteristik dieses products dient, dass die antwortsschreiben der völker und einzelpersonen an Brutus möglichst genau die reihenzahl seiner briefe wiedergeben; ja dass einer seiner correspondenten, Damas, in einem übermass yon courtoisie den worten des Brutus eine gleiche anzahl worte entgegenstellt.

R. Hercher.

\section{Druckversehen.}

Heft 2, 380 f. steht leider dreimal „am achten der Iden”, während es natürlich ,an achten der Iden" heissen sollte. 